Linha D'Água (Online), São Paulo, v. 30, n. 2, p. 51-69, out. 2017

\title{
LETRAMENTO LITERÁRIO MULTIMODAL E INTERMIDIÁTICO: A CONSTRUÇÃO DO LEITOR/SCRIPTOR DE UMA NOVA MIDIA
}

\section{LITERARY MULTIMODAL AND INTERMEDIA LITERACY: BUIDING A READER/ SCRIPTOR OF NEW MEDIAS}

\author{
Ana Luiza Ramazzina Ghirardi* \\ Universidade Federal de São Paulo, Guarulhos, SP, Brasil
}

\begin{abstract}
Resumo: Esse artigo apresenta uma experiência didática realizada com estudantes da graduação de Letras (Português, PortuguêsFrancês, Português-Inglês, Português-Espanhol), da Escola de Filosofia, Letras e Ciênnias Humanas/UNIFESP, campus Guarulhos, durante 0 segundo semestre de 2015. 0 objetivo do curso, intitulado "Adaptação Literária e Multimodalidade", era o de levar 0 aprendiz a se apropriar dos conceitos fundamentais de multimodalidade e de intermidialidade por meio de análise de adaptaçõoes literárias em diversas mídias. A estratégia didática adotada foi a de convidar 0 aprendiz a tomar 0 papel de autor/scriptor de uma transposição intermidiática multimodal através do manuseio de uma obra literária pertencente a uma mídia verbal textual (mídia-fonte) com o objetivo de reconfigurá-la em uma mídia qualificada - filme, HQ, stop-motion etc. (mídia-alvo) a partir de sua apropriação da linguagem literária textual.
\end{abstract}

Palavras-chave: experiência didática; multimodalidade; intermidialidade; adaptação literária; autor/scriptor.

Abstract: This paper describes and discusses a course for undergraduate language students (Porruguese, Portuguese-French, Portuguese-English, Portuguese-Spanish) held at the Escola de Filosofia, Letras e Ciências Humanas/UNIFESP, at the second semestre of 2015. The goal of the course, entitled "literary Adaptation and Multimodality" was to help students understand, through the analysis of literary adaptations to different media, the key concepts in multimodality and intermedia literacy. The teaching strategy adopted was that of inviting the student to become a author/scriptor of a muldimodal intermedia transposition, reconfiguring the text of written literature (source media) into different media - film, comics, stop-motion (source media).

Keywords: Teaching Practices; Muldimodality; Intermedia Literacy; Literary Adaptation; Author/Scriptor.

* Professora doutora da Universidade Federal de São Paulo - UNIFESP, Guarulhos, SP, Brasil; alramazzina@uol.com.br 
Linha D'Água (Online), São Paulo, v. 30, n. 2, p. 51-69, out. 2017

\section{Introdução}

Em "Sintaxe da Linguagem Visual", a professora de comunicação Donis Dondis questiona o modo como um experiente leitor de linguagem verbo-textual traduz essa expertise para a leitura verbal de imagens. Segundo o autor,

O alfabetismo visual jamais poderá ser um sistema tão lógico e preciso quanto a linguagem. As linguagens são sistemas inventados pelo homem para codificar, armazenar e decodificar informações. Sua estrutura, portanto, tem uma lógica que o alfabetismo visual é incapaz de alcançar. (DONDIS, 2014, p. 18-20)

O autor indica, ainda, que, enquanto o "alfabetismo verbal" se dá em um processo dividido em etapas, o "alfabetismo visual" mostra-se carente de uma organização precisa (a comunicação visual humana não apresenta um conjunto de normas e preceitos, metodologia e sistema com critérios definidos). Esta constatação leva à suposição de que a sociedade atual está diante de um longo caminho a percorrer para uma consolidação e uma ampliação (se viável) do letramento visual de leitores. $\mathrm{O}$ autor afirma que

[...] a expressão visual é o produto de uma inteligência extremamente complexa, da qual temos, infelizmente, um conhecimento reduzido. O que vemos é uma parte fundamental do que sabemos, e o alfabetismo visual pode nos ajudar a ver o que vemos e a saber o que sabemos (DONDIS, 2014, p. 27, itálico do autor).

Partindo da problemática apontada pela autora e das formas de linguagem das quais a literatura textual tem se revestido em novas mídias (consagrados textos literários são reconfigurados e apresentados em novas linguagens como filmes, HQ videogames etc.), o curso "Adaptação Literária e Multimodalidade" foi estruturado para ajudar o aprendiz a formar um repertório conceitual que facilite o desenvolvimento de seu letramento visual.

O desenho do curso propunha três etapas de formação, com os seguintes objetivos específicos: 
Linha D'Água (Online), São Paulo, v. 30, n. 2, p. 51-69, out. 2017

- Primeira etapa: capacitar o aprendiz a analisar e realizar a transposição multimodal;

- Segunda etapa: a partir do referencial teórico adquirido, levar o aprendiz a se tornar um criador/manuseador/scriptor de uma adaptação literária para a linguagem multimodal;

- Terceira: realizar uma reflexão crítica sobre o percurso ao longo do curso e a forma como afetou as noções anteriores do aprendiz de sua noção de original/adaptação/multimodalidade/intermidialidade.

Ao longo do curso, o texto literário tornou-se "um laboratório de práticas discursivas" (GUILLEMETTE, 2009, tradução nossa) e capacitou o aprendiz para essa última etapa. O aprendiz tomou consciência de que os textos são maleáveis, móveis e que podem se concretizar em diferentes formas conservando uma identidade permanente que o deixa reconhecível.

A avaliação da produção dos estudantes bem como o desenvolvimento de suas ações ao longo do curso apoioaram-se no quadro de competências LLM (littératie médiatique multimodale) elaborado por Lacelle e Lebrun (2014). ${ }^{1}$

Dessa forma, em um primeiro momento, os estudantes foram expostos a diferentes percursos no universo da adaptação literária, de modo a poder descobrir a possibilidade de uma pluralidade das formas para um mesmo texto. Em seguida, eles se muniram de instrumentos/suportes teóricos que lhes permitissem compreender o que se entende por identidade do texto e os fatores que o fazem ser reconhecido em diferentes mídias. Finalmente, a partir do manuseio e da desmaterialização do texto literário escrito, foram convidados a reconfigurá-lo em uma outra linguagem a partir de sua apropriação.

Esse percurso visava permitir que o aprendiz desenvolvesse um letramento visual que o habilitasse a ler mais confortavelmente textos literários cristalizados em novas mídias.

1 O letramento midiático multimodal (LMM) é dirigido às competências relativas à decodificação, à análise e à avaliação de diversas mídias, impressas ou eletrônicas. Segundo as autoras do quadro, as mídias eletrônicas abolem progressivamente a fronteira entre leitor e scriptor. 
Linha D'Água (Online), São Paulo, v. 30, n. 2, p. 51-69, out. 2017

O curso adotou como referencial teórico as contribuições de estudiosos como Badouard (2015), Genette (1982), Hébert et Guillemette (2009), Maingueneau (2014), Saemmer (2015), Vanoye (2011), entre outros.

\section{Formulação do curso}

O curso apresentou como espinha dorsal um "laboratório de práticas discursivas" (GUILLEMETTE, 2009, tradução nossa). A proposta consistia em levar o aprendiz à construção de uma nova linguagem escrita a partir da mídia-fonte (texto literário) capaz de estruturar a mídia-alvo selecionada (p.ex.: filme, HQ). O aprendiz, simultaneamente, desempenhava o papel de leitor, levado à construção de um letramento para a leitura de uma literatura de linguagem visual, identificando a pluralidade de uma mesma obra e o papel de scriptor ${ }^{2}$, interferindo no texto escrito e realizando uma nova linguagem representada pela literatura intermidiática multimodal. ${ }^{3}$

À medida que o aprendiz percorria as adaptações e se apropriava dos conceitos e do manuseio das variações do texto escrito, ele se munia para concretizar a tarefa final do curso. O percurso geral foi dividido em três grandes etapas que se desenvolveram a partir de um eixo principal.

A primeira etapa tinha como objetivo explorar diferentes conceitos de adaptação e o modo pelo qual o aprendiz compreendia a questão da identidade permanente do texto dentro do processo adaptativo. Constatou-se que, em geral, os estudantes acreditavam que toda adaptação deveria ser a mais fiel possível ao seu texto-fonte e que mudar significativamente poderia revelar uma adaptação malfeita.

Após a conscientização de diferentes possibilidades de transformação do texto, uma segunda etapa foi proposta com o objetivo de levar o aprendiz a percorrer a adaptação como exercício prático. Mais adiante, um exemplo prático desse momento será relatado.

Em seguida, uma terceira etapa confrontou o aprendiz com três formas de adaptação e lançou uma discussão sobre noções de fidelidade e intertextualidade.

2 O termo latim "scriptor" foi eleito nesse artigo com o objetivo de abarcar tanto o sentido de um copista quanto o de um escritor, um autor.

3 O curso deu ênfase a textos clássicos como Germinal, de Zola, O estrangeiro, de Camus etc. 
Linha D'Água (Online), São Paulo, v. 30, n. 2, p. 51-69, out. 2017

Durante todo o processo, as três etapas gravitaram em torno do eixo principal do curso. Desde o início, o aprendiz tinha consciência de que se confrontaria com uma experiência de apropriação do texto literário monomodal e que deveria realizar seu manuseio para uma mídia multimodal ao longo da evolução do curso. Vale dizer, o aprendiz encontrava-se em um processo de letramento que o tornava ao mesmo tempo leitor e scriptor da literatura multimodal. Isto o levava a entender que a memória de um texto literário está estreitamente ligada à memória do objeto/mídia em que tal texto aparecia.

\section{Explorando adaptações e novas mídias}

Como gatilho para o início do curso, uma discussão sobre o sentido dos verbos adaptar, transformar, mudar buscou jogar luz sobre a "noção de transformação" e a suposição de um ponto de partida fixo (mídia-alvo). A partir dos conceitos de Vanoye (2011), a adaptação foi apresentada, então, como a manutenção de características essenciais de um objeto primeiro (mídia-fonte).

No que diz respeito ao universo fílmico, Vanoye afirma, em L'adaptation littéraire au cinéma, que "o texto fonte é um trampolim para o devaneio dos cineastas. Eles se apropriam desse texto, o mimam, o destroem, o refazem mais e mais vezes" (VANOYE, 2011, p. 9, tradução nossa). ${ }^{4} \mathrm{O}$ autor compara a palavra trabalho, que para ele "lembra o trabalho da madeira, o de toda matéria sujeita ao tempo, ao meio ambiente, à ação dos homens" com a do sentido da adaptação que, segundo o autor, "transforma as formas" (tradução nossa). ${ }^{5}$

Nessa etapa do curso, houve uma apropriação da ideia de Vanoye, ampliando-a além das fronteiras da adaptação para o cinema. Assim, o aprendiz também viveu um processo no qual foi exposto à possibilidade de se moldar ao tempo, ao espaço e à ação dos debates, transformando-se em um novo leitor/scriptor; vivendo

\footnotetext{
4 Le texte source est alors un tremplin à la rêverie des cinéastes. Ils s'en emparent, le choient, le détruisent, le refont encore et encore (VANOYE, 2011, p. 9).

5 [...] le mot travail évoque le travail du bois, celui de toute matière soumise au temps, à l'environnement, à l'action des hommes. Or l'adaptation transforme les formes (VANOYE, 201 1, p. 9).
} 
Linha D'Água (Online), São Paulo, v. 30, n. 2, p. 51-69, out. 2017

uma experiência que tinha por objetivo the descortinar a possibilidade de uma adaptação, tornar mais complexa sua percepção frente à obra literária.

Além da ideia de transformação sugerida por Vanoye, levou-se também em conta o conceito figurado de palimpsesto ${ }^{6}$ sugerido por Genette (1982) que acredita que este represente toda obra derivada de uma obra anterior, por transformação ou imitação. ${ }^{7}$ Genette vai além e sugere o termo "transmodalização" no sentido de transformação de um texto no modo de representar uma obra de ficção. ${ }^{8}$ Com esse conceito, foi possível ao aprendiz realizar mudanças no texto escrito, acreditando na possibilidade de uma mídia derivada e não copiada da mídia-fonte.

\section{Colocando a mão na massa}

Após a discussão e conscientização de diferentes possibilidades de transformação da linguagem literária textual, foi proposta ao aprendiz a experiência de um percurso de adaptação como exercício prático. Nessa etapa, a "madeira a ser trabalhada, manuseada" é representada pelo texto.

O ponto de partida foi a reflexão de Gabriela Hardtke Böhm (2004) sobre adaptação de uma obra literária clássica. $\mathrm{O}$ objetivo proposto era o de transformá-la em uma narrativa para crianças. O sujeito adaptador deveria também ter a preocupação de tomar o lugar do outro, o leitor-alvo, para melhor executar sua tarefa. O romance Germinal (capítulo um, segunda parte), de Emile Zola foi tomado como objeto a ser transformado, manuseado.

O aprendiz foi, então, confrontado com o texto de Zola e assumiu o lugar do sujeito adaptador: sua tarefa era a de transformar um texto integral em leitura fácil. O romance, considerado uma obra complexa e com características próprias da

6 Papiro ou pergaminho cujo texto primitivo foi raspado, para dar lugar a outro https:// houaiss.vol.com.br/pub/apps/www/v3-0/html/index.htm\#1, consultado em 01/04/2017

$7 \quad[. .$.$] on entendra donc, au figuré, par palimpsestes (plus littéralement : hypertextes) toutes les$ œuvres dérivées d'une œuvre antérieure, par transformation ou par imitation (GENETTE, 1982).

8 Par transmodalisation, j'entends donc plus modestement une transformation portant sur ce que I'on appelle, depuis Platon et Aristote, le mode de représentation d'une œuvre de fiction : narratif ou dramatique. Les transformations modales peuvent être a priori de deux sortes : intemodales (passage d'un mode à l'autre) ou intramodales (changement affectant le fonctionnement interne du mode) [GENETTE, 1982, p. 395-396]. 
Linha D'Água (Online), São Paulo, v. 30, n. 2, p. 51-69, out. 2017

narrativa do século XIX, deveria ser transformado em um texto acessível a um público que, conforme se acredita, teria dificuldades em compreender o texto original, seja por questão de faixa etária, seja pelo idioma, seja por seu repertório cultural. Ao manusear o texto na tentativa de criar uma "versão simplificada", o aprendiz percebeu que era possível eliminar passagens sem comprometer a boa compreensão da narrativa de base, bem como acrescentar elementos que modulassem o texto de forma a torná-lo mais acessível ao público-alvo. O aprendiz buscou uma solução por meio do ensinamento de Böhm (2004) que dedica três partes de seu capítulo para indicar que adaptar não é só eliminar, mas também acrescentar e divertir.

Esse processo de transformação do fragmento de Germinal em leitura fácil, ajudou o aprendiz a tomar consciência de um primeiro modo de transformação de texto e de perceber que o adaptador se vê diante de múltiplas escolhas ao realizar uma nova versão da obra em questão. Ao final da atividade, o aprendiz confrontou seu trabalho com a adaptação já feita por Silvana Salerno (2001) e refletiu sobre sua atitude como leitor/scriptor/adaptador. Nessa etapa, o aprendiz surpreendeu-se ao se deparar com o texto de Salerno que, apesar de ter apenas procedido à exclusão de longas descrições - sem interferir muito em outras dimensões do texto - conseguiu, ainda assim, um resultado relevante.

Ao comparar os textos, houve uma sobreposição de ideias que tornou a tarefa mais interessante. Segundo Genette,

[... a arte de "fazer o novo com o velho" tem a vantagem de produzir objetos mais complexos e mais saborosos do que os produtos "feitos de propósito": uma função nova se sobrepõe e se confunde com uma estrutura antiga, e a dissonância entre esses dois elementos copresentes dá seu sabor ao todo (1982, p. 556). ${ }^{9}$

Dando sequência a essa etapa, o aprendiz apropriou-se do conceito de multimodalidade introduzido por meio de textos que interagem com diferentes artifícios

9 [...] l'art de 'faire du neuf avec du vieux' a l'avantage de produire des objets plus complexes et plus savoureux que les produits 'fait exprès' : une fonction nouvelle se superpose et s'enchevêtre à une structure ancienne, et la dissonance entre ces deux éléments coprésents donne sa saveur à l'ensemble. (GENETTE, 1982, p. 556) 
Linha D'Água (Online), São Paulo, v. 30, n. 2, p. 51-69, out. 2017

(imagem, gesto, som etc.) para o estabelecimento de uma interação comunicacional ${ }^{10}$, com o objetivo de levar o aprendiz a reconhecer o conceito de multimodalidade e ler com mais conforto textos em que interagem imagem e palavra.

Em Discurso e análise do discurso, Dominique Maingueneau (2015) afirma que a comunicação é "multimodal", ela "mobiliza simultaneamente vários canais" (p. 160); o autor destaca ainda que

Realmente, o que mais contribuiu para impor as problemáticas ligadas à multimodalidade é certamente o fato de que a porção dos enunciados "escritos" que comportam elementos icônicos cresce sem cessar, o que afeta a própria noção de "texto", tanto que se fala, às vezes, de "iconotexto" para designar as produções semióticas em que imagem e fala são indissociáveis. (2015, p. 160).

Levando em consideração a proposta de uma possibilidade plural de canais de comunicação, foi possível idealizar a formação de um "alfabetismo visual" para instrumentalizar o aprendiz em direção à leitura literária multimodal.

A partir dessa perspectiva multimodal do texto, deu-se início a uma nova etapa que encontrou em um primeiro momento na linguagem multimodal das HQs seu objeto de trabalho. Para que o aprendiz pudesse perceber de forma mais concreta essa multiplicação de linguagens em uma mídia como a HQ o texto de Zola foi retomado e, dessa vez, foi proposta ao aprendiz uma experiência de apropriação do texto literário monomodal (mídia-fonte) e seu manuseio em direção a uma linguagem multimodal (mídia-alvo).

A tarefa consistia em adaptar a linguagem textual de Zola em uma linguagem de sequências fixas, a HQ mídia que conjuga diferentes códigos semióticos que se integram e constroem em novas perspectivas para o sentido do texto narrativo.

Para isso, tomou-se a mídia HQ Germinal, tomo 1, de Philippe Chanoinat et Jean-Michel Arroyo (Editions Adonis, 2010, p. 9-12) correspondente ao mesmo texto já utilizado pelos estudantes para a adaptação para leitura fácil (2a parte do primeiro capítulo). Toda a linguagem textual da HQ foi apagada previamente dos balões das vinhetas e apresentada ao aprendiz que deveria fazer sua própria

10 Revistas, hieróglifos egípcios, vitrais medievais etc.

GHIRARDI, A. L. R. Letramento literário multimodal e intermidiático: a construção do leitor/scriptor 
adaptação do texto a partir das imagens e diferentes símbolos já utilizados. O aprendiz percebeu, por meio desse processo, que alguns elementos narrados por Zola já estavam explícitos por intermédio de imagens ou onomatopeias nessa nova mídia. Foi um momento de descoberta da imagem e de sua integração/substituição ao texto escrito. $O$ trabalho final foi discutido em grupo, o que auxiliou na compreensão da escolha do produto final (p. ex.: muitos estudantes perceberam que haviam explicitado por linguagem escrita o que já existia em linguagem visual).

Essas duas experiências, a adaptação do texto original para leitura fácil e em seguida para HQ foram essenciais para a sequência do curso, pois, ao se tornar ator/scriptor, o aprendiz envolveu-se na transformação do texto, em seu processo e suas implicações.

Como conclusão dessa etapa, o texto de Pina, em Literatura em Quadrinhos: Arte e Leitura hoje, serviu como referencial teórico. A autora indica três tipos possíveis de adaptação literária:

Há basicamente três tipos de adaptações: aquelas que, didaticamente, "podem" substituir a obra-fonte, pois reproduzem o texto integral e pouco interferem na produção original; há as que investem intensamente na criatividade dos adaptadores e selecionam e combinam as partes que lhes interessam do texto-base, interferindo no enredo, quer pelo movimento das partes, quer pelo traço, pelas cores; há, por fim, as que misturam os interesses artísticos, pedagógicos e mercadológicos, usando personagens infantis consagrados, por exemplo, para viver personagens literárias clássicas (Clássicos Disney e Turma da Mônica) (PINA, 2012, p. 69).

A partir dessa ideia, foram apresentadas ao aprendiz outras possibilidades de adaptação para HQ com os objetivos específicos que Pina indica. Duas versões do texto clássico de Dom Juan, de Molière para HQ: uma que reproduz fielmente o texto e acrescenta imagens, outra em que o autor cria novos cenários e utiliza parte do texto de Molière. E ainda, como último exemplo, uma versão de Romeu e Julieta, de Shakespeare, adaptada por Mauricio de Souza com os personagens da Turma da Mônica. Ter manuseado o texto de Zola para a mídia HQ confrontado o resultado obtido com a mídia já existente e refletido sobre as diferentes possibilidades de adaptação de um texto clássico escrito para a HQ, levou o aprendiz a 
Linha D'Água (Online), São Paulo, v. 30, n. 2, p. 51-69, out. 2017

considerar possibilidades no cenário de reconfiguração textual para outros formatos que até então não faziam parte de seu repertório enciclopédico.

\section{Fidelidade, intertextualidade, transtextualidade}

Uma nova etapa do curso confrontou o aprendiz com essas três diferentes formas de adaptação. Uma discussão foi proposta a partir das ideias de Stam (2006), em Teoria e prática da adaptação: da fidelidade à intertextualidade. ${ }^{11}$ Nesse artigo, o autor indica que tem como objetivo "desconstruir a doxa não declarada que sutilmente constrói o status subalterno da adaptação (e da imagem cinematográfica) vis-à-vis os romances (e o mundo literário), para então apontar perspectivas alternativas." Essa discussão foi enriquecida pelo uso dos conceitos de Genette acerca da transtextualidade e das relações transtextuais. ${ }^{12}$ Assim, a adaptação do texto literário foi trabalhada por dois vieses.

No primeiro viés, discutiu-se a criação de um roteiro de filme. A base foram as ideias de Syd Field (2014), segundo o qual "um roteiro é uma história contada por meio de imagens, diálogos e descrições, sempre localizada no âmbito de uma estrutura dramática" (FIELD, 2014, p. 31). Como atividade prática, o aprendiz deveria ler o conto "A cartomante", de Machado de Assis e aplicar as teorias de Field para criar seu próprio roteiro. A proposta consistia em levar o aprendiz à construção de uma nova linguagem escrita a partir da mídia-fonte (texto literário), com o objetivo de realizar uma mídia intermediária (roteiro) capaz de estruturar a mídia-alvo (filme). Ao ler o conto considerando os argumentos descritos por Field para a elaboração de um roteiro, o aprendiz conseguiu perceber como essa mídia intermediária não corresponde ao texto original e como ela é fundamental para realizar a mídia-alvo.

\footnotetext{
11 https://periodicos.ufsc.br/index.php/desterro/article/view/2175-8026.2006n51 p19 (consultado em 26 de abril de 2017)

12 Je dirais plutôt aujourd'hui, plus largement, que cet objet est la transtextualité, ou la transcendance textuelle du texte, que je définissais déjà, grossièrement, par « tout ce qui le met en relation, manifeste ou secrète, avec d'autres textes (GENETTE, 1982, p. 7).
} 
Em seguida, o aprendiz pode cotejar o roteiro que fabricou ao já realizado por Wagner de Assis. ${ }^{13} \mathrm{O}$ objetivo de comparação com trabalhos já realizados e consagrados mostrou-se de grande utilidade em todas as etapas percorridas pelo aprendiz, pois servio como ancoragem para que ele pudesse entender melhor suas ideias e realizações. Como conclusão dessa etapa, houve a projeção do filme produzido a partir do roteiro de Assis ${ }^{14} \mathrm{e}$ foi discutida a importância do roteiro realizado antes da concretização de uma adaptação cinematográfica.

Em seguida, foi proposta uma nova adaptação cinematográfica com outro objetivo: sua concepção a partir de mais de um texto-fonte e as possibilidades que podem gerar para diversas novas mídias. O segundo viés gravitava, então, em torno da variação de um mesmo tema: $A$ bela adormecida. A partir do conto e da versão mais conhecida dos estudantes brasileiros, a de Perrault, o aprendiz tomou conhecimento de três versões realizadas por diferentes culturas: Sol, Lua e Talia (1634), de Giambattista Basile; $A$ bela adormecida (1697), de Charles Perrault; e Rosicler (1812), dos Irmãos Grimm.

Os três contos foram cotejados a partir de um roteiro de leitura comparativo em que o estudante deveria preencher um quadro sinóptico (quadro 1) que deixava mais claras as características de cada narrativa.

\begin{tabular}{c|c|c|c} 
& $\begin{array}{c}\text { Sol, Lua e Tália } \\
\text { Giambattista Basile }\end{array}$ & $\begin{array}{c}\text { A Bela Adormecida no } \\
\text { Bosque } \\
\text { Charles Perrault }\end{array}$ & $\begin{array}{c}\text { Rosicler } \\
\text { Irmãos Grimm } \\
\text { Família }\end{array}$ \\
Premonição/dons & 1697 & 1812 \\
Objeto perigoso & & & \\
\hline Fadas & & & \\
\hline & &
\end{tabular}

13 ASSIS, Wagner. A cartomante. Roteiro - História, Origem e Comentários. São Paulo, Imprensa Oficial, 2005

14 Filme baseado no conto homônimo de Machado de Assis, lançado em 2004, dirigido por Wagner de Assis e Pablo Uranga, disponível em https://www.youtube.com/watch?v=2qP3J-JMyfQ

GHIRARDI, A. L. R. Letramento literário multimodal e intermidiático: a construção do leitor/scriptor 
Linha D'Água (Online), São Paulo, v. 30, n. 2, p. 51-69, out. 2017

(continuação)

\begin{tabular}{|c|c|c|c|}
\hline & $\begin{array}{c}\text { Sol, Lua e Tália } \\
\text { Giambattista Basile } \\
1634\end{array}$ & $\begin{array}{c}\text { A Bela Adormecida no } \\
\text { Bosque } \\
\text { Charles Perrault } \\
1697\end{array}$ & $\begin{array}{c}\text { Rosicler } \\
\text { Irmãos Grimm } \\
1812\end{array}$ \\
\hline \multicolumn{4}{|l|}{ Decreto } \\
\hline \multicolumn{4}{|l|}{ Princesa (nome) } \\
\hline \multicolumn{4}{|l|}{$\begin{array}{l}\text { Desencadeamento do } \\
\text { feitiço/profecia }\end{array}$} \\
\hline \multicolumn{4}{|l|}{ Consequências } \\
\hline \multicolumn{4}{|l|}{ Destino da princesa } \\
\hline \multicolumn{4}{|l|}{$\begin{array}{l}\text { Destino dos pais/do } \\
\text { castelo }\end{array}$} \\
\hline \multicolumn{4}{|l|}{ Príncipe/rei } \\
\hline \multicolumn{4}{|l|}{ Quebra do feitiço } \\
\hline \multicolumn{4}{|l|}{$\begin{array}{c}\text { Continuação após a } \\
\text { quebra do feitiço? Qual? }\end{array}$} \\
\hline Moral & & & \\
\hline
\end{tabular}

Quadro 1: roteiro de leitura comparativo (RAMAZZINA, 2015)

Em seguida, houve a projeção da versão Disney (1959) para o cinema. Já de posse dos dados do quadro sinóptico, o aprendiz pode compreender melhor as escolhas feitas nessa adaptação, que se baseou nos contos de Perrault e dos Irmãos Grimm. Como conclusão dessa etapa, a versão Maléfica (2014) foi analisada com ênfase em outras possiblidades de adaptação a partir de um mesmo tema (nessa versão, a malvada feiticeira é personagem central e se mostra capaz de amar Aurora e não desejar sua morte). 
Linha D'Água (Online), São Paulo, v. 30, n. 2, p. 51-69, out. 2017

\section{Adaptação, midialidade e intermidialidade}

Com o objetivo de fechar essa etapa, o aprendiz tomou contato com conceitos de adaptação, midialidade e intermidialidade introduzidos por Gaudreault e Marion. Para o aprendiz, compreender o percurso que uma mídia transcorre em direção a outra, os conceitos de fabula, syuzhet e mídia ${ }^{15}$ foram estudados a partir do embasamento teórico de Tomashevsky (1973).

Como ilustração dessa problemática, o aprendiz tinha como tarefa ler o conto Bola de Sebo (1880), de Maupassant. Em sala de aula, o conto foi "recontado" e "reconstruído" a partir da perspectiva do aprendiz. À medida que as frases iam tomando forma e retomavam a história de Maupassant, o aprendiz ia compreendendo a apropriação do conto por Chico Buarque de Holanda na música Geni e o Zepelin, composta para o musical Opera do Malandro (1978). Mesmo que as duas versões apresentem histórias diferentes em contextos diferentes, os estudantes entenderam que se tratava da reconfiguração de um mesmo texto difundida em diferentes mídias.

$\mathrm{O}$ aprendiz compreendeu que fábula e mídia mostram-se completamente independentes uma em relação à outra, syzhet vai arbitrar um tipo de relação entre as duas, ou seja, um produto, resultado da encarnação de um substrato narrativo em mídia.

\section{Scriptor de uma nova mídia}

Como atividade para avaliação, um trabalho em grupo em três etapas (realizadas ao longo do curso) foi proposto ao aprendiz. Desse modo, o curso se propôs a oferecer ao aprendiz uma experiência de apropriação do texto literário monomodal (mídia-fonte) e seu manuseio para uma linguagem multimodal (mídia-alvo), o que o transformou em leitor/scriptor desse processo.

15 Segundo Tomashevsky, fabula é o conjunto de fatos associados transmitido em uma obra específica; syuzhet é o que acontece de fato, o modo pelo qual o leitor toma consciência do que aconteceu, o texto como se mostra em uma mídia específica, equivalente à fábula após o processo de midiatização; e mídia é o suporte expressivo, o veículo semiótico, abstrato (TOMASHEVSKY, 1973).

GHIRARDI, A. L. R. Letramento literário multimodal e intermidiático: a construção do leitor/scriptor 
Linha D'Água (Online), São Paulo, v. 30, n. 2, p. 51-69, out. 2017

À medida que o aprendiz percorria as adaptações e se apropriava dos conceitos e manuseio do texto escrito, ele se munia para a execução da tarefa final concebida em três etapas.

$\mathrm{Na} 1^{\text {a }}$ etapa, após um terço do curso, o aprendiz com seu grupo deveria escolher uma obra literária textual para realizar uma transposição multimodal; escolher qual transposição seria executada: linguagem original (escrita) -> linguagem da transposição (multimodal); antecipar desafios: Quais? Por quê? eleger o referencial teórico para justificar as escolhas; justificar a escolha do referencial teórico (Por quê?)

$\mathrm{Na} 2^{\mathrm{a}}$ etapa, após dois terços do curso, todos os conceitos estudados ao longo das aulas serviram como pilar para o aprendiz, no momento em que ele se tornou criador/manuseador/scriptor de sua adaptação literária em direção a uma linguagem multimodal. Nessa fase, o aprendiz tinha como tarefa apresentar uma primeira versão da adaptação; explicitar dificuldades afrontadas (vão ao encontro das dificuldades antecipadas? Em quais termos?); evidenciar quais foram as principais escolhas feitas pelo grupo e qual o fundamento teórico selecionado para essas escolhas.

Com isso, na $3^{\mathrm{a}}$ etapa, última semana do curso, o aprendiz deveria apresentar a obra completa realizada pelo grupo à classe; indicar as fontes teóricas utilizadas e, finalmente, responder à questão: "Como essa experiência impactou sua noção de original/adaptação/multimodalidade/intermidialidade?

\section{Conclusão do percurso}

Como trabalho de conclusão do curso (quadro 2), os estudantes apresentaram as seguintes adaptações (alguns exemplos do resultado desse trabalho encontram-se no anexo desse artigo - figuras 1 e 2): 
Linha D'Água (Online), São Paulo, v. 30, n. 2, p. 51-69, out. 2017

\begin{tabular}{ccc} 
MÍDIA-FONTE (ESCRITA) & GÊNERO & MÍDIA-ALVO \\
\hline Alice no país das maravilhas (1865), Lewis Carroll & Romance & Peça de teatro \\
O diário de Anne Frank (1947), Anne Frank & Romance & Página Facebook \\
Oferta (1925-27), Oswald de Andrade & Poesia & Seção de fotos \\
Continuidade dos parques (1956), Cortázar & Conto & Curta-metragem \\
O jantar (1960), Clarice Lispector & Conto & Curta-metragem \\
Familiar (1946), Jacques Prévert & Poesia & Stop-motion \\
Opatinho feio (1843), Hans Christian Andersen & Conto & Diário íntimo \\
O alienista (1882), Machado de Assis & Romance & Stop-motion \\
O lixo (1994), Luís Fernando Veríssimo & Conto & HQ digital \\
Alucinação (1942), Cećlia Meireles & Poesia & Curta-metragem \\
Moça na repartição (1962), Fernando Sabino & Crônica & Curta-metragem \\
Quem conta um conto (1873), Machado de Assis & Conto & Peça de teatro \\
Instruçóes in Histórias de Cronopios e Famas (1962), Cortázar & Conto & Curta-metragem
\end{tabular}

Quadro 2: trabalhos de conclusão do curso (RAMAZZINA, 2015)

A atividade teve por objetivo, de um lado, habilitar o aprendiz a construir suas próprias estratégias de leitura dos textos literários monomodal e multimodal; de outro, permitir-lhe repensar as fronteiras imaginadas entre língua e literatura e transformá-lo em construtor de uma nova linguagem em uma nova mídia.

Os resultados do curso indicam que, por meio do exercício contínuo de manuseio de diferentes linguagens e sua materialidade, o aprendiz desenvolve uma consciência mais aguda da relação fusionada língua/gênero/mídia e de seu papel ativo como leitor/scriptor/produtor de sentido.

Ao fim do curso, o aprendiz se deu conta de que suas ações no espaço virtual e o manuseio dos recursos multimídias o transformaram em ator não apenas no processo de apropriação e de construção dos sentidos do literário, mas também na criação de expressões multimídias de suas descobertas como leitor/escritor/ produtor de sentido.

Esse processo transformou essa fusão em um encontro, como observa Saemmer (2015) a respeito da recepção do texto digital e que aqui se toma para explicitar esse encontro com o texto escrito adaptado para uma nova mídia:

GHIRARDI, A. L. R. Letramento literário multimodal e intermidiático: a construção do leitor/scriptor 
A recepção do texto digital é definida como um encontro, ao menos parcial, entre um texto com seus processos retóricos e suas formas na página-tela, e o horizonte de espera de um leitor dotado de suas capacidades, centro de interesse e referências culturais, membro de uma sociedade com a qual ele partilha uma ou várias línguas, valores, prática e imaginários (SAEMMER, 2015, p. 37-38, tradução nossa). ${ }^{16}$

Pode-se afirmar, ainda, que os recursos multimídias utilizados pelo aprendiz, parte integrante desse processo, além de permitirem o alargamento das formas de apropriação do literário em sala de aula, puderam, igualmente, se prestar como veículo para reatualizar a perspectiva da literatura como ferramenta para ler o mundo em que se insere o aprendiz.

Segundo Badouard (2015), essa mídia tem, acima de tudo, a característica do "manuseio" o que permite a possibilidade da transformação do texto e da interatividade com o leitor. $\mathrm{O}$ autor afirma que

Compreender essa dimensão do digital, se apropriar dela, é tomar consciência de que os escritos podem se reconfigurar ao infinito e então estarem afinados no tempo ou serem transformados, que os percursos de navegação podem se adaptar ao internauta, e que as mídias oferecem uma possibilidade de manuseio, a partir do momento em que repousam em um formato binário (BADOUARD, 2015, p. 55-56, tradução nossa). ${ }^{17}$

Pode-se afirmar que, ao longo do curso, por ter se apropriado do texto escrito e ter manuseado esse texto, reconfigurando-o em uma nova mídia, o aprendiz pode desenvolver uma leitura mais aprofundada de novas formas de expressão literária, transformando-se em um leitor com novas perspectivas de letramento.

16 La réception du texte numérique est définie comme une rencontre, au moins partielle, entre un texte avec ses procédés rhétoriques et ses formes sur la page-écran, et l'horizon d'attente d'un lecteur doté de ses capacités, centre d'intérêt et référents culturels, membre d'une société avec laquelle il partage une ou plusieurs langues, valeurs, pratiques et imaginaires (SAEMMER, 2015, p. 37-38).

17 Comprendre cette dimension du numérique, se l'approprier, c'est prendre conscience que les écrits peuvent se reconfigurer à l'infini et donc être affinés dans le temps ou être transformés, que les parcours de navigation peuvent s'adapter à l'internaute, et que les médias offrent une possibilité de manipulation à partir du moment où ils reposent sur un format binaire (BADOUARD, 2015, p. 55-56).

GHIRARDI, A. L. R. Letramento literário multimodal e intermidiático: a construção do leitor/scriptor 
Linha D'Água (Online), São Paulo, v. 30, n. 2, p. 51-69, out. 2017

\section{Referências}

BADOUARD, R. «Programmer ou être programmé»: les enjeux citoyens de l'écriture numérique in PETITJEAN, A.-M., HOUDART-MEROT, V. In : Numérique et écriture littéraire, Mutation des pratiques. Paris: Hermann Éditeurs, 2015, p. 47-60.

BÖHM, G. H. Peter Pan para crianças brasileiras: a adaptação de Monteiro Lobato para a obra de James Barrie. In: João Luís C. T. Ceccanti. Leitura e Literatura infanto-juvenil: Memória de Gramado. São Paulo, ANEP, 2004, p. 58-71.

DONDIS, A. D. Sintaxe da linguagem visual. Tradução por Jefferson Luiz Camargo. São Paulo: Martins Editora Livraria Ltda, 1991/2014.

FIELD, Syd. Roteiro - os fundamentos do roteirismo. Tradução por Alice Leal. Curitiba, Arte \& Letra Editora, 2014.

GENETTE, G. Palimpsestes - la littérature au second degré. Paris: Editions du Seuil, 1982.

HÉBERT, L., GUILLEMETTE, L. Intertextualité, interdiscursivité et intermédialité. Québec : Les Presses de l'Université Laval, 2009.

LACELLE, N. \& LEBRUN, M. (2014) La littératie médiatique multimodale : réflexions sémiologiques et dispositifs concrets d'application. http://www.forumlecture.ch/myUploadData/files/2014_2_Lacelle_Lebrun.pdf (consultado em 26 de abril de 2017)

MAINGUENEAU, D. Discours et Analyse du Discours. Paris : Armand Colin, 2014.

SAEMMER, A. Rhétorique du texte numérique : figures de la lecture, anticipations de pratiques. Villeurbanne, Presses de l'Enssib, coll. « Papiers », 2015.

VANOYE, F. L'adaptation de l'cuvre littéraire au cinéma. Paris : Armand Colin, 2011.

Recebido em 30/04/2017.

Aprovado em 30/08/2017.

GHIRARDI, A. L. R. Letramento literário multimodal e intermidiático: a construção do leitor/scriptor 
Linha D'Água (Online), São Paulo, v. 30, n. 2, p. 51-69, out. 2017

\section{ANEXOS}
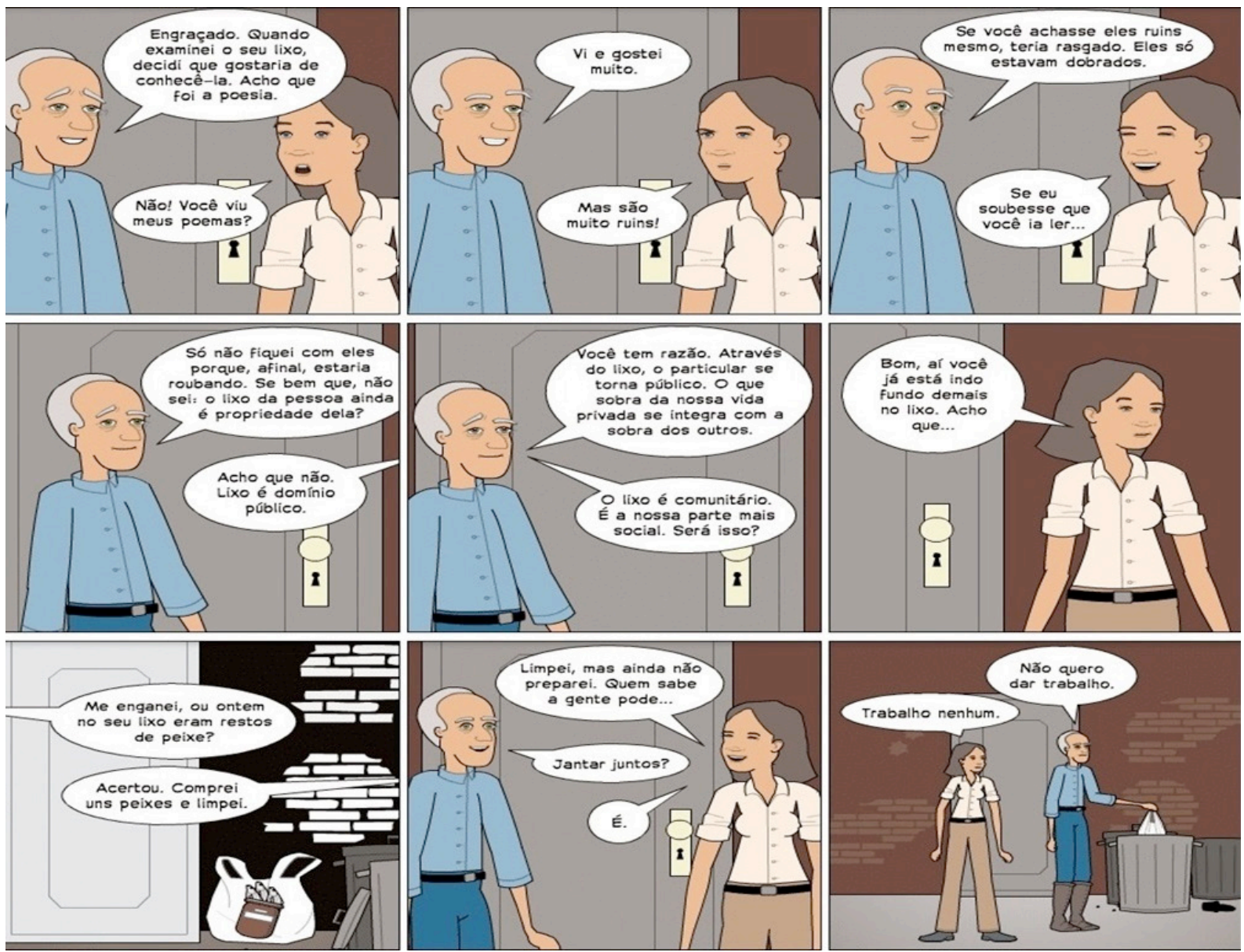

Figura 1: Excerto de HQ feita para a adaptação do conto O lixo, de Luís Fernando Veríssimo. 
Linha D'Água (Online), São Paulo, v. 30, n. 2, p. 51-69, out. 2017

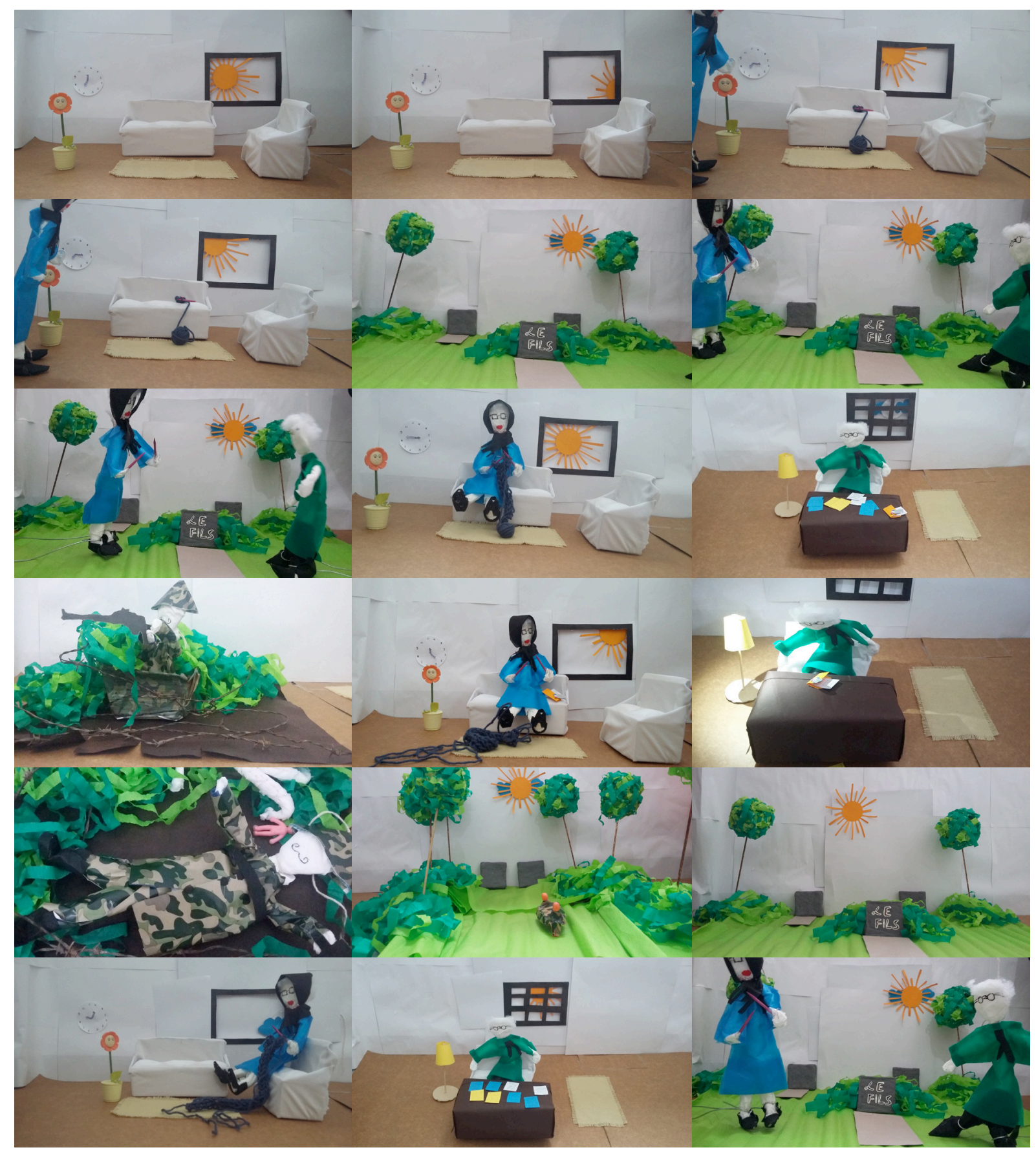

Figura 2: Imagens selecionadas da adaptação em stop-motion do poema Familiale de Jacques Prévert. 